\title{
Contraceptive use patterns among Spanish single youth
}

\author{
Teresa Castro Martín
}

Department of Demography, Institute of Economics and Geography, Spanish Council for Scientific Research, Madrid, Spain

Objective To examine sexual and contraceptive use patterns, including method choice, among unmarried youth in Spain.

Method The analysis is based on the 1999 Youth Survey. The analytical sample comprised 696 never-married sexually experienced women aged 15-24 and 1070 men. Logistic regression was used to assess the influence of various socio-demographic factors on contraceptive use, and multinomial logistic regression was used to examine the determinants of method choice.

Results Given the trend towards earlier sexual initiation and increasing marriage postponement, sexual activity prior to marriage has become the norm in Spain. Nine out of 10 sexually active single youth reported contraceptive use at their last intercourse. Differentials across social subgroups were small, with the exception of those based on educational level. Young women and men with more than one partner in the previous year and those not currently in a stable relationship were more likely to engage in unprotected intercourse. Regarding the choice of method, the analysis revealed that, although condom is the dominant method, there is a tendency to shift to the pill with increasing age and relationship stability.

Conclusion The level of contraceptive protection among unmarried youth is reasonably high, but a nontrivial proportion of youth engage in unprotected sexual activity.

K E Y W O R D S Contraception, Youth, Unmarried, Spain

\section{N T R O D U C T I O N}

In the course of the past two decades, contraceptive patterns have changed dramatically in Spain. Until 1978, the use, sale, and distribution of contraceptives, as well as the dissemination of family planning information, were forbidden by law. Although veiled transgressions of this restrictive legislation were normally tolerated, access to modern contraception was very limited and largely confined to married couples and well-off sectors of the population. In fact, withdrawal accounted for half of all contraceptive use until the late 1970s. With the adoption of a democratic Constitution in 1978, important legislative reforms were introduced, including the legalization of contraception. In the following decades, Spain underwent a sharp reduction in fertility ${ }^{1}$, in which access to modern contraception did undoubtedly play a major role. The overall contraceptive rate increased from $47.1 \%$ in 1977 to $58.4 \%$ in 1985 and to $81 \%$ in $1995^{2}$. 
Although the risk of unwanted pregnancy remains significant ${ }^{3,4}$, the estimated unmet demand of family planning in the overall population is currently among the lowest in Europe 5 .

The monitoring of contraceptive prevalence rates has traditionally focused on the contraceptive patterns of women of reproductive age in marital or consensual unions ${ }^{6}$. The underlying reason is that most estimates are based on demographic and fertility surveys, which provide extensive information on contraceptive use patterns, but rarely collect data on sexual behavior. Women who are married or in consensual union can be assumed to be sexually active, but this assumption cannot be made for the entire unmarried population. Since information on sexual exposure is crucial to calculate meaningful estimates of contraceptive protection rates, but is often unavailable for unmarried youth, this important segment of the population tends to be excluded in comparative studies of contraceptive prevalence. This is particularly problematic, because young people usually display the highest rates of unwanted pregnancies ${ }^{7}$, abortion ${ }^{8}$ and exposure to HIV risks ${ }^{9}$.

The constraints imposed by traditional data shortage on young people's sexual behavior have lessened recently. Worldwide concern about the HIV/AIDS epidemic has moved the issue of sexual health to the forefront of the research and policy agenda, promoting efforts of data collection since the 1990s. In the European context, the Fertility and Family Surveys-conducted in 24 countries during the 1990s-and several national sexual health surveys conducted in relation with the HIV epidemic $^{10}$ provide a valuable framework for comparative analysis.

The Plan of Action adopted at the Cairo International Conference on Population and Development in $1994^{11}$ has also contributed to acknowledge the centrality of sexual and reproductive health-including the avoidance of unintended pregnancies and sexually transmitted infections (STIs) - to health in general, and the right of young people to lead healthy, risk-free sexual lives. Accordingly, efforts to monitor youth's sexual and reproductive health have received increasing support during the past decade. As an illustration, a recent European Parliament report on sexual and reproductive health and rights ${ }^{12}$ has recommended the European Commission to develop a database based on harmonized indicators to monitor and evaluate progress on sexual and reproductive health, paying special attention to youth needs.

In Spain, the contraceptive patterns of unmarried youth have received limited scientific scrutiny ${ }^{13}$. However, several indicators provide indirect hints to monitor youth's sexual and contraceptive behavior. In a comparative framework, Spain displays a relatively low rate of teenage pregnancy ${ }^{14}$. In 2001, among 15-19-year-olds, the fertility rate was 9.9 births per 1000 women, the pregnancy rate was 18.2 per 1000 women, and the abortion rate was 8.3 abortions per 1000 women, which are below the levels found in most European countries ${ }^{15}$. However, other indicators, such as the abortion ratio (proportion of pregnancies, excluding miscarriages, that end up in abortion), which was $45.5 \%$ for the 15-19 age group and $31.9 \%$ for the $20-24$ age group in 2001, indicate that there is still an unmet need for contraceptive protection within this sector of the population. In addition, Spain remains one of the countries in Western Europe where AIDS incidence is highest: 71.3 cases per million population diagnosed in $2002^{16}$.

The objective of this study is to estimate the level of contraceptive protection among unmarried youth and to identify the socio-demographic factors that influence contraceptive use as well as method choice. The analysis is based on the 1999 Youth Survey. Although youth policy in Spain covers the ages between 14 and 30 , we have followed the definition of 'youth' established by the United Nations General Assembly for the International Youth Year in 1985 and reflected in all statistics published by the United Nations system. Hence, the analysis will focus on never-married sexually experienced women and men aged 15-24.

\section{DATA AND METHODS}

The monitoring of contraceptive prevalence rates in Spain has been typically based on data collected in nationally representative demographic surveys, such as the 1985 Fertility Survey, the 1995 Family and Fertility Survey, and the 1999 Fertility Survey, and more recently in surveys specifically focused on contraception $^{17}$. However, since most surveys cover the entire population of reproductive age, information on sexual activity among the unmarried population is not always collected, and if collected, sample sizes for sexually active unmarried youth tend to be too small to perform meaningful analyses. 
The analysis presented here is based on the Youth Survey $1999^{18}$, a nationally representative random sample of 6492 men and women aged 15-29. This survey, conducted by the Centre for Sociological Research (CIS), collected broad information on youth lifestyles, including the timing of sexual initiation, recent sexual activity, number and type of partners, and contraceptive use. The data were collected through personal interviews, and several portions of the main questionnaire were self-administered to facilitate the collection of sensitive information. Given its relatively large sample size, separate analyses by gender, marital status, and age groups are feasible.

In this study, we focus on the contraceptive patterns of never-married men and women aged 15-24 who have ever had sexual intercourse; 72 never-married individuals who were cohabiting with their partner at the time of the interview, 369 individuals who did not answer whether they had ever engaged in sexual intercourse, and 28 individuals for whom data on contraceptive use were missing were excluded from the analysis. This left an analytical sample of 696 women and 1070 men.

Some limitations of the data should be noted. First, measurement errors may occur in the reporting of sexual behavior and contraceptive use. Some respondents, for instance, may be reluctant to admit unprotected intercourse. Also, since most contraceptive methods are gender-specific, it is possible that one partner is not aware of the method that the other partner is using. However, several evaluations of surveys on sexual and contraceptive behavior have concluded that the data gathered are usually reliable and merit serious analysis ${ }^{19}$. Second, the survey only collected data on contraceptive use at last intercourse and therefore does not provide information on consistency of contraceptive use, which would be a more meaningful indicator of contraceptive protection. Third, the questionnaire only allowed respondents to report a single contraceptive method; consequently, dual contraceptive use-for example, combined use of condom and pill ${ }^{20}$ — cannot be ascertained.

The prevalence of specific contraceptive methods is determined by two related processes: the decision to use contraception and the choice of a particular contraceptive method. These processes are modeled in this study in two stages. In a first stage, we estimate the overall contraceptive prevalence rate among sexually active unmarried youth. We also use logistic regression analysis to examine subgroup differentials and to identify those demographic and social factors which exert a significant influence on contraceptive protection patterns. The dependent variable is coded 1 if the respondent reported any contraceptive used at last intercourse and 0 otherwise. To ease interpretation, the results are expressed in terms of odds ratios, which are the exponential value of the logit coefficient and are to be interpreted relative to the omitted category. Odds ratios larger than one indicate a greater likelihood of contraceptive use than the reference category, and conversely, odds ratios smaller than one imply a lower likelihood of contraceptive use.

In a second stage, we estimate method-specific prevalence rates and use multinomial logistic regression to examine the determinants of method choice. In the multinomial logit models, the dependent variable is contraceptive method type, which is classified into four categories: condom, pill, other method, no method. We present results for three contrasts: the odds of using condoms versus using no contraception, the odds of using the pill versus using no contraception, and the odds of using the pill versus the condom. Since the use of female condoms is practically negligible in Spain, the term 'condom' refers always to the male condom.

The explanatory variables include socio-demographic covariates (age, level of education, type of school attended, town size, living arrangement, family structure, religiosity and political positioning) and sexual behavior indicators (age at first intercourse, number of partners in the previous year and type of current partnership). Most variables have been documented in the literature to influence contraceptive decision-making and behavior ${ }^{21}$. Separate analyses are conducted for young women and men in order to explore gender-specific differentials ${ }^{22}$.

\section{R E S U L T S}

\section{Patterns of sexual behavior among youth}

Spain has recently undergone profound changes affecting sexual and partnership patterns. Previous studies based on the 1995 Fertility and Family Survey ${ }^{23}$ have documented a trend towards earlier sexual initiation, particularly among women, narrowing the traditional gender gap in age at first intercourse. By contrast, entry into marriage has been increasingly postponed ${ }^{24}$, 
expanding the interval between entry into sexual activity and entry into marriage. Data from the 2001 Census confirm that recent cohorts spend most of their youth years in an unmarried state: $94.4 \%$ of women and $97.9 \%$ of men aged 15-24 have never married.

According to the 1999 Youth Survey data, sexual experience is not widespread in the 15-19 age group (only $24 \%$ of women and $30.1 \%$ of men in this age group reported to have ever engaged in sexual intercourse), but it is much more common among $20-24$-year-olds (57.9\% of single women and $80.5 \%$ of single men in this age group reported sexual experience) (Figure 1). Once the transition to sexual activity is made, youngsters are likely to remain sexually active. According to survey responses, 85.3\% of sexually experienced women and $83.3 \%$ of sexually experienced men aged 15-24 reported sexual activity in the 12 months preceding the interview.

Gender differentials in the timing of sexual debut, which used to be large in the past-as a consequence of the double standard of sexual behavior for men and women-are nowadays relatively narrow. We have constructed life tables of the transition to first sexual intercourse for the whole sample of men and women interviewed, and the resulting median age at first intercourse is 20.6 for women and 18.8 for men. If we take into account that, according to 2001 vital statistics, the mean age at first marriage is 28.4 for women and 30.4 for men, it is obvious that the life span of premarital sexual activity had widened considerably, making the focus on unmarried youth's contraceptive needs clearly warranted.

\section{Contraceptive protection among single youth}

Table 1 presents contraceptive prevalence rates among sexually experienced unmarried youth. According to these data, the level of contraceptive protection among single Spanish youth is relatively high, in the range of $87-90 \%$. Differentials by age and gender are relatively minor.

From the data in Table 1, it is clear that the main contraceptive method used by unmarried youth is the condom, followed at some distance by the pill. The rest of the methods are practically unused. The reliance on efficient methods is much higher among unmarried than among married persons. According to the 1995 Fertility and Family Survey, for example, $12 \%$ of married women relied on withdrawal ${ }^{2}$. The fact that the condom prevails over all other contraceptive options is a positive feature, since this method can prevent both unintended pregnancy and STIs transmission.

Nearly half of condom users reported that they had used a condom at last intercourse only for contraceptive purposes, and roughly the other half reported that they had used condoms both for contraceptive purposes and for protection from STIs or AIDS. The prevention of STIs/HIV is rarely reported as the only reason to use condoms.

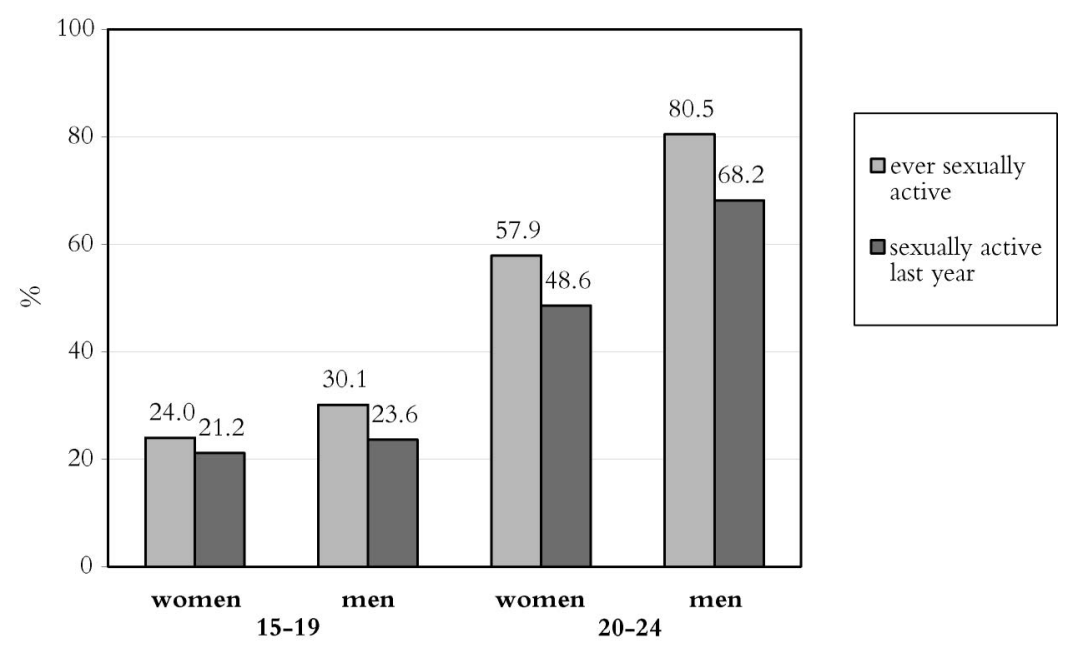

Figure 1 Proportion of young women and men sexually experienced and sexually active in the past year, by age group 
Table 1 Contraceptive prevalence rates among sexually experienced youth, according to gender and age group, 1999

\begin{tabular}{|c|c|c|c|c|}
\hline & \multicolumn{2}{|c|}{ Women } & \multicolumn{2}{|c|}{ Men } \\
\hline & $15-19$ & $20-24$ & $15-19$ & $20-24$ \\
\hline & $\% *$ & $\% *$ & $\% *$ & $\% *$ \\
\hline $\begin{array}{l}\text { Used contraception at last } \\
\text { intercourse }\end{array}$ & 89.6 & 88.5 & 87.1 & 89.8 \\
\hline \multicolumn{5}{|l|}{ Contraceptive method used } \\
\hline Condom & 78.8 & 68.4 & 82.3 & 80.8 \\
\hline Pill & 9.6 & 17.5 & 3.3 & 7.1 \\
\hline Emergency contraception & 0.0 & 0.2 & 0.4 & 0.0 \\
\hline Intrauterine device & 0.0 & 0.5 & 0.0 & 0.3 \\
\hline Withdrawal & 0.0 & 0.1 & 0.0 & 0.1 \\
\hline Calendar rythm method & 0.0 & 0.0 & 0.0 & 0.1 \\
\hline No answer & 1.2 & 1.8 & 1.2 & 1.5 \\
\hline No method & 10.4 & 11.5 & 12.9 & 10.2 \\
\hline \multicolumn{5}{|c|}{ Among condom users, reason to use condoms } \\
\hline Prevention of pregnancy & 44.8 & 48.4 & 46.8 & 47.1 \\
\hline Prevention of STIs/HIV & 1.0 & 3.3 & 7.3 & 5.1 \\
\hline Both & 54.3 & 48.3 & 46.0 & 47.8 \\
\hline$n$ & 224 & 472 & 300 & 770 \\
\hline
\end{tabular}

*All percentages are weighted according to sample weights

\section{Factors influencing contraceptive protection}

The first panel in Table 2 presents the percentage distribution of the analytical sample, i.e. sexually experienced unmarried women and men aged 15-24, according to socio-demographic characteristics. This distribution reflects some of the remarkable social transformations experienced by Spanish recent cohorts: a large majority of youth continue schooling beyond the compulsory level — which was raised from age 14 to age 16 in 1990-, remain in the parental home and seldom report religious practice. Although the socio-demographic profile of the female and male sample is very similar, some differentials can be noted. Young women have a higher level of educational attainment than young men (reversing the prevailing pattern in the past), report an older age at first sexual intercourse, are less likely to have engaged in more than one partnership in the previous year, and are more likely to be currently in a stable relationship than young men.

The second panel of Table 2 presents the results of the logistic regression model of contraceptive use, specifically, the adjusted odds ratios of using any contraceptive method at last intercourse. Overall, the results show a large homogeneity in contraceptive use among socio-demographic subgroups. A large number of variables entered in the model show no statistically significant effect on the odds of contraceptive use once the rest of the covariates are taken into account, suggesting that differentials based on those variables are relatively minor. Among women, for example, increasing age, living with parents, family structure, degree of religiosity, political positioning, or timing of sexual initiation show no statistically significant influence on recent contraceptive use. There are, however, some factors that are significantly associated with higher contraceptive use. Among them, the strongest effect corresponds to education, one of the associations most consistently reported in the literature $^{25}$. The higher her educational level, the more likely a young woman is to use contraception. Specifically, the probability of using contraception among college-educated young women is four times larger (adjusted odds ratio $(\mathrm{AOR})=4.21$ ) than among women who have not proceeded beyond compulsory schooling. 
Table 2 Percentage distribution of ever sexually active youth aged 15-24 according to sociodemographic characteristics and adjusted odds ratios (AOR) from logistic regression analyses of contraceptive use at last sexual intercourse $\dagger$

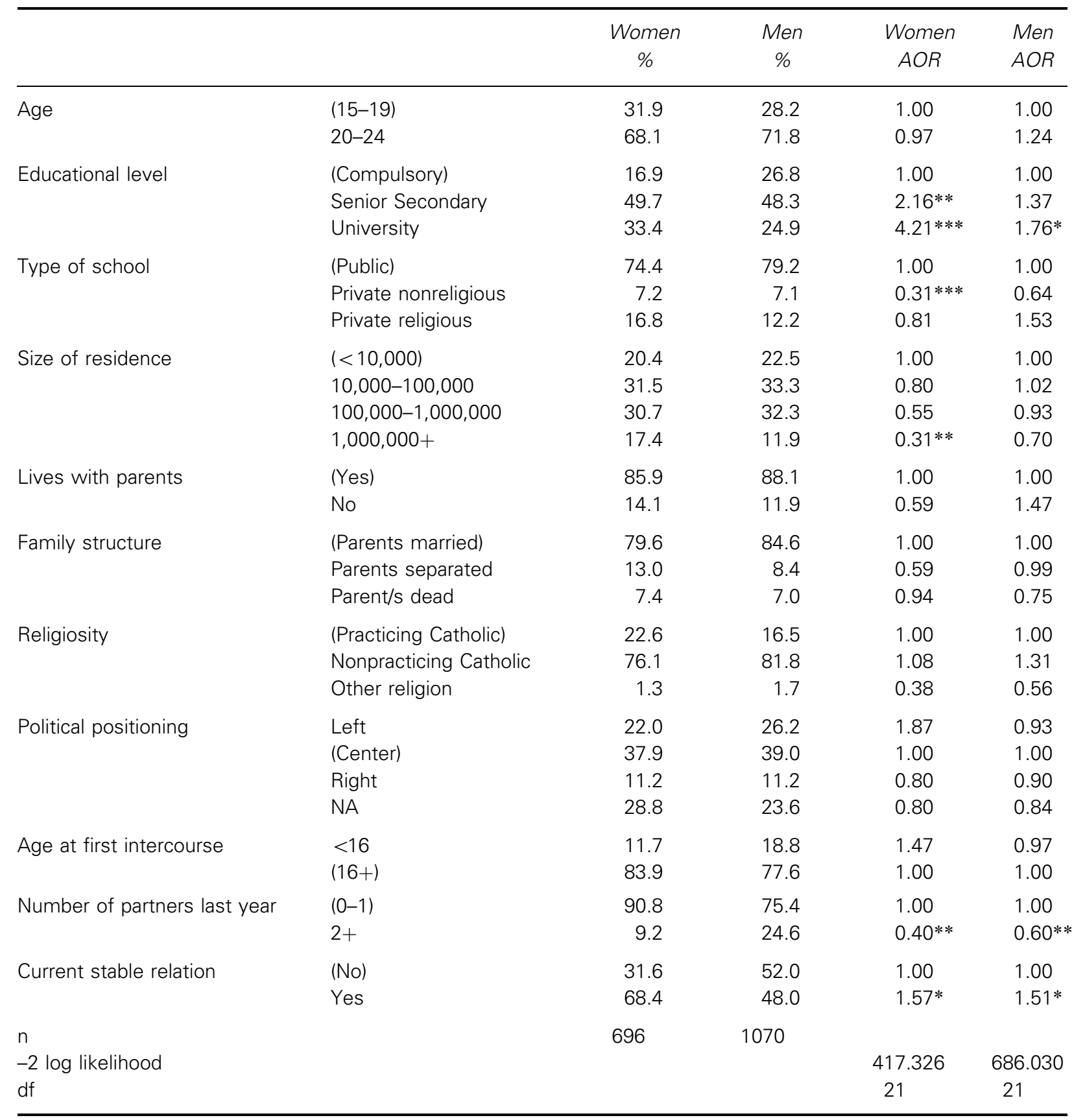

$\uparrow$ Percentages are weighted and may not add to 100 because of nonresponse. Reference categories are in parentheses. Significance levels: $* p<.10, * * p<.05, * * * p<.01$

There are, however, some unanticipated findings, such as the significantly lower likelihood of using contraception among women who attended a private nonreligious school compared to those who attended a public school, and among those who reside in a large city compared to those who reside in a small town. Prior studies have also highlighted the relevance of partnership type on contraceptive use patterns ${ }^{26}$. In this 
regard, the survey analysis reveals that it is precisely those young women more exposed to risk of STIs, i.e. those who had two or more partners in the previous year and those who are not currently in a stable relationship, who are less likely to use contraception.

The results for men do not depart much from women's. Contraceptive use does not vary significantly with age, parental coresidence, family structure, religiosity, political positioning or timing of sexual initiation, either by type of school attended or by town size. Educational attainment does have a positive impact on contraceptive use, although its effect is weaker than that recorded for women: college-educated young men are nearly twice $(\mathrm{AOR}=1.76)$ as likely to use contraception than men who left the educational system after completing the compulsory level. Similarly to women, young men who have had two or more partners in the preceding year and those who are not currently in a stable relationship are significantly more likely to engage in unprotected intercourse.

\section{Factors influencing contraceptive method choice}

Contraceptive needs change over the life course, and possibly no one method may ever be suitable for the entire life span. The specific-method prevalence rates presented in Table 1 indicated that the condom prevails over all other contraceptive options among single youth. This is probably so because, among available methods, condoms provide dual protection against unplanned pregnancy and STIs, adapt well to the patterns of serial monogamy or sporadic sexual relationships prevailing during youth, are easily accessible at pharmacies or convenience stores, and do not need medical prescription or supervision. Nonetheless, it is documented in the literature that with increasing age and increasing duration in a relationship, many couples switch from condoms to oral contraceptives ${ }^{27}$. Next, we will explore whether this pattern holds among Spanish youth.

Table 3 presents the results of the multinomial logit models on contraceptive method choice. We present here only the contrasts related to the condom and the pill, because the proportion of youth using other methods is too low to permit a meaningful analysis of those methods. The model for young women reveals several interesting findings. Some covariates influence overall contraceptive use but do not favor a method in particular. This is the case of educational attainment: college-educated women are much more likely to use both the condom and the pill than women with a lower education. The same pattern applies to town size, type of school attended, and number of recent partners; these covariates do influence contraceptive use, but the effect is alike for the two methods under consideration.

By contrast, other covariates that influence overall contraceptive use display divergent effects for different contraceptive methods. For example, being in a stable relationship substantially increases $(\mathrm{AOR}=3.09)$ the probability of pill use but not of condom use. Another pattern worth noting is that several covariates that did not show a statistically significant impact on contraceptive use do have an effect on contraceptive choice. For example, increasing age showed no effect on the level of contraceptive protection, but it does have a significant impact on choosing the pill over the condom. Having left the parental home or having separated parents reduces the likelihood of women using condoms but has no significant impact on pill use. Likewise, nonCatholic young women are less likely to use condoms than Catholic women, but are more likely to use the pill, although this latter effect is not statistically significant, possibly due to a small sample size.

Some of the patterns shown by men are similar to women's, but there are some divergences. For example, men's educational attainment significantly increases condom use, but not reliance on partner's pill use. Also, early sexual initiation, which had no significant effect among women, appears to reduce reliance on the pill, but not on condoms among men. Having experienced two or more partnerships in the preceding year reduces the odds of using both the condom and the pill, but much more the latter.

In sum, the simultaneous analysis of specific method use allows a more refined depiction of the impact of the covariates on contraceptive patterns. The results reveal that some factors that do not affect the overall level of contraceptive protection have some bearing on contraceptive method choice. In line with prior studies, we found evidence that, among women and men, increasing age and being in a stable relationship favors the pill over the condom. This pattern has important implications for health, since the pill, although it has a higher theoretical effectiveness against unplanned pregnancies, provides no protection against STIs, including HIV. 
Table 3 Adjusted odds ratios (AOR) from multinomial logistic regression analyses on contraceptive method used at last sexual intercourse $\dagger$

\begin{tabular}{|c|c|c|c|c|c|c|c|}
\hline & & & Women & & & Men & \\
\hline & & $\begin{array}{l}\text { Condom } \\
\text { vs. none }\end{array}$ & $\begin{array}{c}\text { Pill vs. } \\
\text { none }\end{array}$ & $\begin{array}{c}\text { Condom vs. } \\
\text { pill }\end{array}$ & $\begin{array}{l}\text { Condom } \\
\text { vs. none }\end{array}$ & $\begin{array}{c}\text { Pill vs. } \\
\text { none }\end{array}$ & $\begin{array}{c}\text { Condom } \\
\text { vs. pill }\end{array}$ \\
\hline Age & $(15-19)$ & 1.00 & 1.00 & 1.00 & 1.00 & 1.00 & 1.00 \\
\hline & $20-24$ & 0.85 & 1.84 & $0.46 * * *$ & 1.17 & $3.73 * * *$ & $0.31 * * *$ \\
\hline Educational level & (Compulsory) & 1.00 & 1.00 & 1.00 & 1.00 & 1.00 & 1.00 \\
\hline & Senior Secondary & $2.02 * *$ & $3.56 * * *$ & 0.57 & 1.34 & 1.57 & 0.85 \\
\hline & University & $4.19 * * *$ & $4.90 * * *$ & 0.86 & $1.78 *$ & 1.25 & 1.43 \\
\hline Type of school & (Public) & 1.00 & 1.00 & 1.00 & 1.00 & 1.00 & 1.00 \\
\hline & Private nonreligious & $0.30 * * *$ & $0.25 * *$ & 1.22 & 0.62 & 0.80 & 0.78 \\
\hline & Private religious & 0.79 & 1.03 & 0.77 & 1.47 & $2.89 * *$ & $0.51 *$ \\
\hline Size of residence & $(<10,000)$ & 1.00 & 1.00 & 1.00 & 1.00 & 1.00 & 1.00 \\
\hline & $10,000-100,000$ & 0.85 & 0.56 & 1.51 & 1.07 & 0.91 & 1.18 \\
\hline & $100,000-1,000,000$ & 0.54 & 0.49 & 1.11 & 0.95 & 1.03 & 0.93 \\
\hline & $1,000,000+$ & $0.29 * *$ & $0.30 * *$ & 0.96 & 0.71 & 0.90 & 0.78 \\
\hline Lives with parents & (Yes) & 1.00 & 1.00 & 1.00 & 1.00 & 1.00 & 1.00 \\
\hline & No & $0.55 *$ & 0.72 & 0.77 & 1.45 & 0.73 & 1.98 \\
\hline Family structure & (Parents married) & 1.00 & 1.00 & 1.00 & 1.00 & 1.00 & 1.00 \\
\hline & Parents separated & $0.50 *$ & 1.03 & $0.48 * *$ & 0.97 & 1.11 & 0.88 \\
\hline & Parent/s dead & 0.81 & 1.47 & 0.56 & 0.76 & 0.94 & 0.81 \\
\hline Religiosity & (Practicing Catholic) & 1.00 & 1.00 & 1.00 & 1.00 & 1.00 & 1.00 \\
\hline & Nonpracticing Catholic & 1.02 & 1.48 & 0.69 & 1.28 & 2.01 & 0.64 \\
\hline & Other religion & $0.18^{*}$ & 2.52 & $0.07 * * *$ & 0.48 & 1.96 & 0.25 \\
\hline Political positioning & Left & 1.97 & 1.51 & 1.31 & 0.91 & 1.12 & 0.81 \\
\hline & (Center) & 1.00 & 1.00 & 1.00 & 1.00 & 1.00 & 1.00 \\
\hline & Right & 0.72 & 1.02 & 0.70 & 0.87 & 1.57 & 0.56 \\
\hline & NA & 0.83 & 0.68 & 1.22 & 0.83 & 0.68 & 1.22 \\
\hline Age at first intercourse & $<16$ & 0.63 & 0.86 & 0.74 & 1.10 & $0.30 * * *$ & $3.66^{* * *}$ \\
\hline & $(16+)$ & 1.00 & 1.00 & 1.00 & 1.00 & 1.00 & 1.00 \\
\hline Number of partners last year & $(0-1)$ & 1.00 & 1.00 & 1.00 & 1.00 & 1.00 & 1.00 \\
\hline & $2+$ & $0.43 * *$ & $0.34 * *$ & 1.27 & $0.63 * *$ & $0.23 * * *$ & $2.73^{* *}$ \\
\hline Current stable relation & (No) & 1.00 & 1.00 & 1.00 & 1.00 & 1.00 & 1.00 \\
\hline & Yes & 1.32 & $3.09 * * *$ & $0.43^{* * *}$ & 1.35 & $6.23^{* * *}$ & $0.22 * * *$ \\
\hline $\mathrm{n}$ & & 696 & & & 1070 & & \\
\hline -2 log Likelihood & & 938.072 & & & 1090.33 & & \\
\hline df & & 63 & & & 63 & & \\
\hline
\end{tabular}

$\dagger$ TReference categories are in parentheses. Significance levels: $* p<.10, * * p<.05, * * * p .01$

\section{I S C U S S I O N}

The development of effective educational and public health interventions in the area of sexual and reproductive health depends upon accurate information concerning sexual and contraceptive behavior of the target population. A proper understanding of the factors associated with contraceptive method choice is also important for evaluating and improving the quality of reproductive health care. This study 
aimed at providing an analytical portrayal of an underresearched area: the sexual and contraceptive behavior of unmarried Spanish youth. We have documented a relatively high level of contraceptive protection: nine out of 10 sexually active single youth reported contraceptive use during their last sexual intercourse, and nearly all of them used effective methods.

Although this is an encouraging finding, the fact that approximately $11 \%$ of respondents reported unprotected sexual intercourse should not be overlooked. According to the 2001 Census, the unmarried population aged 15-24 numbered 2,598,054 women and $2,825,323$ men. If we assume that the proportion of those who are sexually experienced is similar to the proportion in the 1999 survey $(39.8 \%$ of women and $54 \%$ of men aged 15-24), this means a population of 113,743 young women and 167,824 young men exposed to the risk of unplanned pregnancy and STIs.

More importantly, the survey analyzed only measured contraceptive use at last sexual intercourse, but the level of consistent contraceptive use is usually lower than the level measured at only one episode, particularly regarding condom use. Since the consistency of contraceptive use is critical to the avoidance of unplanned pregnancies and STIs, it is likely that the young population eventually exposed to risk is larger than the former estimates imply.

Regarding the factors that predict contraceptive use, in general we found little variation across sociodemographic groups. The nonsignificance of factors such as family structure, religiosity or political positioning suggests that once a society attains a high level of contraceptive protection, differentials based on social and cultural characteristics tend to weaken. An exception to this pattern of convergence across social boundaries is educational attainment, which continues to exert a strong influence, particularly among women, on contraceptive protection.

Unmarried youth usually have distinct contraceptive method preferences due to unsteady partnership dynamics. Increased awareness of the risk of HIV has also altered the context of contraceptive choice. The data revealed that the condom is the leading method among unmarried youth, and this is a desirable option since it minimizes the dual risks of unintended pregnancy and STIs. However, further research is needed to ascertain whether consistency of use is similar among users of condoms and users of other contraceptive methods. The data also revealed a growing shift from condoms to the pill, with increasing age and partnership stability. Since oral contraceptives do not protect against STIs, including $\mathrm{HIV}$, prevention programs must take into account the increasing preference for the pill over barrier methods with increasing age among unmarried youth, and evaluate the need to encourage dual protection.

The level of protection reported by women and men is practically identical. Furthermore, although most methods that are highly effective against pregnancy are female-controlled and the method most commonly used to prevent STIs is male-controlled, gender differentials in specific-method prevalence rates are not large, suggesting that young women and men share the same concerns. With regard to the factors that influence method choice, the analysis revealed both commonalities and differentials among young women and men. For example, education has a much stronger effect on both condom use and pill use among women than among men.

In sum, remarkable progress has been achieved in Spain with regard to youth contraceptive protection. However, some caveats remain; among them, the nonexistence of a comprehensive survey conducted on a regular basis for monitoring and evaluating sexual and reproductive health, as recommended by the recent European Parliament report on sexual and reproductive health and rights ${ }^{12}$. Also, given that family planning is not fully integrated into the health system and that sexual education is practically absent from the school curricula, there is still room for further improvement in both quantity and quality of familyplanning services. Additional challenges are also ahead. The increasing immigrant population in Spain, many of them unmarried youth, is raising the unmet demand of contraception. As a warning sign, although data on nationality are not collected in the official register of abortions coordinated by the Ministry of Health, some studies based on clinic data reveal that a very large proportion of the abortions performed correspond to young immigrant women ${ }^{28}$. Old and new challenges need to be approached within the broad context of sexual and reproductive health and rights.

\section{A C K N O W L E D G M E N T S}

This research is part of a project entitled 'Private lives, public co-responsibility: new family patterns in today's Spain and tomorrow's Europe' supported by a grant from the BBVA Foundation. 


\section{REFERENCES}

1. Billari F, Castiglioni M, Castro Martín T, et al. Household and union formation in a mediterranean fashion: Italy and Spain. In Klijzing E, Corijn M, eds. Dynamics of Fertility and Partnership in Europe: Insights and Lessons from Comparative Research. Geneva: United Nations, 2002;Vol. II, 17-41.

2. Ruiz Salguero M, Cabré A, Castro Martín T, et al. Anticoncepción y Salud Reproductiva en España: Crónica de una (R)evolución. Madrid: CSIC, Colección de Estudios Ambientales y Socioeconómicos, 2005.

3. Lete I, Bermejo R, Coll C, et al. Spanish population at risk of unwanted pregnancy: Results of a national survey. Eur J Contracept Reprod Health Care 2003;8(2):75-9.

4. Skouby SO. Contraceptive use and behavior in the $21^{\text {st }}$ century: a comprehensive study across five European countries. Eur J Contracept Reprod Health Care 2004;9: 57-68.

5. Klijzing E. Are there unmet family planning needs in Europe? Fam Plann Perspect 2000;32(2):74-81.

6. United Nations. World Contraceptive Use 2003 Wall Chart. New York: United Nations, 2003.

7. Darroch J, Singh S, Frost J, et al. Differences in teenage pregnancy rates among five developed countries: the roles of sexual activity and contraceptive use. Fam Plann Perspect 2001;33(6):244-50.

8. AGI. Into a New World: Young Women's Sexual and Reproductive Lives. New York: Alan Guttmacher Institute, 1998.

9. UNICEF/UNAIDS/WHO. Young People and HIV/ AIDS: Opportunity in Crisis. New York: United Nations, 2002.

10. Hubert M, Bajos N, Sandfort T, eds. Sexual Behaviour and HIV/AIDS in Europe, Comparisons of National Surveys. London: UCL Press, 1998.

11. United Nations. Report on the International Conference on Population and Development, Cairo, 5-13 September 1994. New York: United Nations, 1995.

12. Van Lancker A. European Parliament Report on Sexual and Reproductive Health and Rights (A5-0223/2002). Strasbourg: European Parliament, 2002.

13. Castilla J, Barrio G, de la Fuente L, et al. Sexual behaviour and condom use in the general population of Spain, 1996. AIDS Care 1998;10(56):667-76.

14. UNICEF. A League Table of Teenage Births in Rich Nations. Innocenti Report Card No. 3. Florence: UNICEF Innocenti Research Centre, 2001.

15. Bajos N, Guillaume A, Kontula, O. Reproductive Health Behaviour of Young Europeans. Strasbourg: Council of Europe, Population Studies No. 42, 2003.
16. European Centre for the Epidemiological Monitoring of AIDS. HIV/AIDS Surveillance in Europe, End-Year Report 2002. Saint-Maurice: Institut de Veille Sanitaire, 2003.

17. Lete I, Bermejo R, Coll C, et al. Use of contraceptive methods in Spain: results of a national survey. Contraception 2001;63:235-8.

18. CIS. Informe sobre la Juventud Española 2000. Estudio CIS $\mathrm{n}^{\circ}$ 2370. Madrid: Centro de Investigaciones Sociológicas, 2000.

19. Dare O, Cleland J. Reliability and validity of survey data on sexual behaviour. Health Transit Rev 1994;4(Suppl): 93-110.

20. Santelli JS, Warren CW, Lowry R, et al. The use of condoms with other contraceptive methods among young men and women. Fam Plann Perspect 1997; 29(6):261-7.

21. Castro Martín T, Njogu, W. A decade of change in contraceptive behaviour in Latin America: a multivariate decomposition analysis. Popul Bull UN 1994;36:81-109.

22. Kowaleski-Jones L, Mott, FL. Sex, contraception and childbearing among high-risk youth: do different factors influence males and females? Fam Plann Perspect 1998;30(4):163-9.

23. Delgado M, Castro Martín, T. Fertility and Family Surveys in Countries of the ECE Region. Standard Country Report: Spain. Geneva: United Nations Economic Commission for Europe, 1999.

24. Castro Martín, T. Matrimonios de hecho, de derecho y en eterno aplazamiento: la nupcialidad española al inicio del siglo XXI. Sistema 2003;175-6:89-112.

25. Castro Martín, T. Women's education and fertility: results from 26 Demographic and Health Surveys. Stud Fam Plann 1995;26(4):187-202.

26. Juárez F, Castro Martín T. Partnership and sexual histories of adolescent males: myths and realities. Presented at the 2004 Annual Meeting of the Population Association of America, Boston, MA, 1-3 April 2004.

27. Ott MA, Adler NE, Millstein SG, et al. The trade-off between hormonal contraceptives and condoms among adolescents. Perspect Sex Reprod Health 2002;34:6-14.

28. Aracil E. No sólo jóvenes y solteras: el recurso a la interrupción voluntaria del embarazo en España y en la Comunidad de Madrid. Inguruak/Revista Vasca de Ciencia Política y Sociología 2003;36:35-53. 